\title{
Carpal tunnel syndrome: what is attributable to work? The Montreal study
}

\author{
Michel Rossignol, Susan Stock, Louis Patry, Benedict Armstrong
}

\begin{abstract}
Objective-To estimate the fraction of carpal tunnel syndrome (CTS) that is attributable to work in the total adult population of the island of Montreal. Methods-The population consisted of 1.1 million people 20 to 64 years of age, with $73.2 \%$ of men and $60.6 \%$ of women employed. The rates of first surgery for CTS were compared between occupational groups and the total adult population with the standardised incidence ratio (SIR) method. Rates of surgery for the island of Montreal were obtained from the provincial data base of payments. The occupational history was obtained from telephone interviews of a sample of surgical cases. The attributable fractions in exposed people were calculated with odds ratios (ORs) obtained from logistic regressions with non-manual workers as the control group.

Results-The surgical incidence of CTS was $0.9 / 1000$ adults. SIRs for all manual workers were 1.9 (95\% confidence interval (95\% CI) 1.4-2.5) in men and 1.8 (95\% CI 1.4-2.2) in women, and the fractions attributable to work were $76 \%(95 \%$ CI 47-88) and 55\% (95\% CI 33-69), respectively. Seven occupational groups were identified as having excess risk of surgical CTS, with fractions attributable to occupation ranging from $75 \%$ to $99 \%$.

Conclusion-Among manual workers on the island of Montreal, $55 \%$ of surgical CTS in women and $76 \%$ in men was attributable to work. Increased risk of surgical CTS was found in seven occupational groups.
\end{abstract}

(Occup Environ Med 1997;54:519-523)

Keywords: carpal tunnel syndrome; occupation; epidemiology; risk

Occupational Health, McGill University, Montreal, Canada

M Rossignol

S Stock

London School of Hygiene and Tropical Medicine, London

B Armstrong

Correspondence to: Dr Michel Rossignol, Occupational Health, 75 de Port-Royal E, Suite 240, Montreal, Quebec, Canada H3L 3T1.

Accepted 26 February 1997 CTS that is attributable to work. Hagberg et al have calculated fractions attributable to exposure ranging from $50 \%$ to $90 \%$ from data pub- lished in 13 epidemiological studies that reported an association between CTS and occupation. Those studies, however, were carried out in specific workplaces and were not representative of the total population of workers. We are not aware of any study that estimated the proportion of cases of CTS attributable to work in a general population. The objective of this study was to provide such an estimate for the total population on the island of Montreal, Canada and to identify occupations at risk.

\section{Method}

Standardised incidence ratios (SIRs) were computed with incident surgical procedures for CTS. Surgery was used because there is a provincial data base (Med-Echo) that records all surgical procedures that are charged to the Quebec Health Insurance Plan. All CTS surgeries put charges through to the Quebec Health Insurance Plan whether performed in public or private clinics. All Quebec residents are covered by the Quebec Health Insurance Plan independently of their employment. The definition of incidence was a first lifetime surgery for CTS. The Med-Echo data base allows computation of incidences for the total adult population of the island of Montreal by age and sex, but does not provide information on occupation. Therefore, a telephone survey was conducted among a prospective sample of patients operated on for CTS for the first time between June 1994 and July 1995.

Consecutive patients were recruited in Montreal from 20 plastic surgeons who agreed to participate in the study. The sites of their practices allowed for representation of all major geographic and socioeconomic regions on the island of Montreal. Inclusion criteria were: first lifetime surgery for CTS, age between 20 and 64 years and residence on the island of Montreal. Lists of all patients operated on by each surgeon in the 12 months of the study were sent to the researchers. Consent was obtained by telephone and followed by an interview with two trained interviewers, on average 2.7 (SD 1.6) months after surgery. The interview included questions on the medical and occupational histories at the time symptoms first started, the history since the beginning of symptoms, and the pain and functional state in the week before surgery. Our questionnaire was an adaptation of that proposed by Katz et $a l^{3}$ and Levine et al. ${ }^{4}$

The SIRs were computed by dividing the number of observed cases in each occupational group in the sample interviewed by the number 
of cases expected in that group, with the incidence of surgical CTS in the total population of Montreal island as reference (MedEcho data base, 1993-4). Denominators by age, sex, and occupation were obtained from the Statistics Canada 1991 Canadian Census for the island of Montreal. The total population was 1.1 million, of which $73.2 \%$ of the men and $60.6 \%$ of women were employed. The SIRs were standardised for age and sex according to the method described in Fleiss ${ }^{5}$ and $95 \%$ confidence intervals ( $95 \%$ CIs) were calculated by the square root method. ${ }^{6}$ The Canadian standard occupational classification of 1981 was used. ${ }^{7}$ A global SIR was computed for all manual workers, from a definition that has been validated in Quebec. ${ }^{8}$ In brief, manual workers included blue collar workers and white collar workers who do manual work such as nurses, waitresses and bar staff, hairdressers, etc.

The attributable fraction in exposed people was computed for each occupation where the SIR reached significance. ${ }^{9}$ Because SIRs represent risks relative to the entire population which includes those occupationally exposed, they are inappropriate for the calculation of attributable fractions. For this purpose, and to more conveniently examine statistical interactions, we carried out logistic regression analyses of incident cases of CTS surgery, with nonmanual workers as the comparison group. As CTS is rare, the Statistics Canada population figures could be considered equivalent to controls in a case-control study. As for the SIRs, the application of this method to a situation in which we had occupational information on only a sample of cases, relies on the assumption that interviewed cases are representative of all cases of surgical CTS. Age and sex were included in all analyses (see table 3 ). The attributable fractions represent the fraction of surgical CTS in a given occupation that is in excess (attributable) of that observed among all non-manual workers (the control group). Interactions between occupation and sex were found to be significant, so all results are presented separately for men and women.

\section{Results}

For the population as a whole, the annual incidence of surgical CTS was 0.9/1000 adults, which represented 969 cases (table 1). The male:female ratio was $1: 3$ and the highest rates were found in women over the age of 45 . Between June 1994 and July 1995, 400 patients were identified by the 20 plastic surgeons participating in the study, and $355(89 \%)$ could be reached by telephone. One patient refused to participate. Of those contacted, 238 patients met the inclusion criteria and were interviewed. Their distribution by age and sex (table 1) was identical to that of all surgical cases in the Quebec data base. The main reason for non-inclusion was age over 64 .

Of the 238 patients interviewed, 224 (94\%) reported having had at least one electrodiagnostic test and described a distribution of their symptoms in the first three digits and the palm of the hand. Half of the patients reported a
Table 1 Incidence of surgical carpal tunnel syndrome, island of Montreal adult population 20 to 64 years of age

\begin{tabular}{clc}
\hline & $\begin{array}{l}\text { Incidenc* } \\
(11000)\end{array}$ & $\begin{array}{l}\text { Number interviewed } \\
n(\%)\end{array}$ \\
\hline Total & 0.9 & $238(100)$ \\
Men & 0.4 & $63(27)$ \\
Age: & & $9(4)$ \\
$20-34$ & 0.2 & $19(8)$ \\
$35-44$ & 0.4 & $21(9)$ \\
$45-54$ & 0.7 & $14(6)$ \\
$55-64$ & 0.9 & $175(74)$ \\
Women & 1.2 & $14(7)$ \\
Age: & & $46(19)$ \\
$20-34$ & 0.3 & $59(25)$ \\
$35-44$ & 1.2 & $53(22)$ \\
$45-54$ & 2.4 & \\
$55-64$ & 2.2 &
\end{tabular}

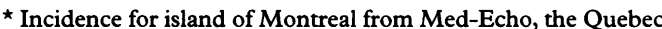
hospital discharge data base, including outpatient surgery, 12 month period 1993-4. Total number of first surgery for CTS = 969. Denominators from Statistics Canada, 1991 census.

duration of symptoms, at the time of surgery, of two years or more. Surgery was performed on the dominant hand in $154(65 \%)$ of the patients. The symptoms in the week preceding the surgery were reported as being present every day in $85 \%$ and interfering with sleep for three nights or more in $71 \%$. Functional limitations were reported as being severe for the following tasks: carrying grocery bags (51\%); unscrewing the cap of a jar $(43 \%)$; carrying a full cup (30\%); writing ( $28 \%)$; and holding a telephone receiver $(27 \%)$. Nonsurgical treatments were received by 139 patients $(58 \%)$ before the surgery. There were no differences in the intensity of symptoms or functional limitations reported in the week preceding surgery among age or occupational groups. A greater proportion of women than men reported the presence of very severe symptoms $(33 \% v 18 \%, \mathrm{P}=0.04)$. This is another reason that the results are presented separately for women and men.

Of all patients interviewed, $53 \%$ reported that when their symptoms first began, they had a job with physically demanding tasks for the hands and wrists, including use of force, vibrating hand held power tools, or exposure to cold. From the medical history, $40 \%$ reported the presence of a medical condition known to be associated with the development of CTS (present when the symptoms first started), the most frequent being diabetes $(12 \%)$, thyroid disease $(9 \%)$, a history of wrist fracture $(8 \%)$, and pregnancy $(5 \%)$.

Of the 238 patients interviewed, $74 \%$ were actively employed at the time symptoms first started ( $70 \%$ of women and $87 \%$ of men), and $53 \%$ were manual workers.

For all manual workers, the SIR was 1.8 (95\% CI 1.4-2.2) in women and 1.9 (95\% CI 1.4-2.5) in men, indicating an incidence almost twofold higher than in the total adult population (table 2). In specific occupational groups, housekeeping occupations had the highest risk and included commercial and domestic categories. Work on a data processer had the second highest risk, and was the only job category among all clerical occupations that showed an increased incidence. Workers at risk in the material handling occupations were those in the packaging subcategory. The food 
Table 2 Standardised incidence ratios (SIR)* of incident surgical carpal tunnel syndrome by occupationt

\begin{tabular}{|c|c|c|c|c|}
\hline \multirow[b]{2}{*}{ Occupation } & \multicolumn{2}{|c|}{ Women } & \multicolumn{2}{|c|}{ Men } \\
\hline & $n$ & $\begin{array}{l}\text { Observed } \\
\text { SIR }(95 \% \text { CI) }\end{array}$ & $n$ & $\begin{array}{l}\text { Observed } \\
\text { SIR }(95 \% \text { CI) }\end{array}$ \\
\hline All manual workers $\ddagger$ & 79 & $1.8(1.4-2.2)$ & 47 & $1.9(1.4-2.5)$ \\
\hline All non-manual workers & 43 & $0.8(0.6-1.1)$ & 8 & $0.5(0.2-0.9)$ \\
\hline Not working & 53 & $0.7(0.5-0.9)$ & 8 & $0.4(0.2-0.8)$ \\
\hline \multicolumn{5}{|c|}{ Specific manual workers categories: } \\
\hline Housekeepers or cleaners & 7 & $7.2(2.8-13.4)$ & 4 & $67.2(17.3-148.0)$ \\
\hline Data processing operators & 5 & $3.1(1.0-6.3)$ & 2 & $11.2(1.1-31.8)$ \\
\hline Material handlers & 6 & $6.0(2.2-11.8)$ & 4 & $5.5(1.4-12.3)$ \\
\hline \multicolumn{5}{|l|}{ Food and beverage: } \\
\hline Processing & 4 & $7.0(1.8-15.3)$ & 2 & $2.7(0.3-7.8)$ \\
\hline Service & 7 & $3.6(1.4-6.7)$ & 1 & $3.0(0.0-11.9)$ \\
\hline Child care & 4 & $3.9(1.0-8.6)$ & 0 & - \\
\hline Lorry and bus drivers & 0 & - & 6 & $3.1(1.1-6.1)$ \\
\hline Hairdressers & 4 & $3.0(0.8-6.7)$ & 1 & $4.2(0.0-16.5)$ \\
\hline Specialised educators & 4 & $2.2(0.6-4.8)$ & 0 & - \\
\hline Manufacturing & 9 & $1.2(0.6-2.1)$ & 6 & $1.6(0.6-3.2)$ \\
\hline Clerical occupations & 30 & $1.0(0.7-1.4)$ & 5 & $1.3(0.4-2.7)$ \\
\hline Health care occupations & 12 & $0.9(0.4-1.4)$ & 1 & $0.7(0.0-2.8)$ \\
\hline Construction workers & 0 & - & 3 & $1.1(0.1-2.8)$ \\
\hline
\end{tabular}

* SIR = standardised incidence ratio $=$ number of observed cases of surgical CTS in interviewed patients divided by number expected from Montreal island adult population incidence. It represents the excess incidence in that occupation, compared with the total population.

† Occupations: categories from the Canadian standard occupational classification, 1980.

¥ Manual workers include blue collar workers and white collar workers with manual work-such as nurses, waitresses and bar staff, hairdressers, etc. ${ }^{8}$

Table 3 Attributable fraction in exposed people (AFE) for incidence of surgical carpal tunnel syndrome by occupation *

\begin{tabular}{|c|c|c|c|c|}
\hline \multirow[b]{2}{*}{ Occupation } & \multicolumn{2}{|l|}{ Women } & \multicolumn{2}{|l|}{ Men } \\
\hline & $\begin{array}{l}\text { ORt } \\
(95 \% C I)\end{array}$ & $\begin{array}{l}A F E \neq(\%) \\
(95 \% C I)\end{array}$ & $\begin{array}{l}\text { ORt } \\
(95 \% C I)\end{array}$ & $\begin{array}{l}A F E \ddagger(\%) \\
(95 \% C I)\end{array}$ \\
\hline All manual workers $\oint$ & $2.2(1.5-3.2)$ & $55(33-69)$ & $4.1(1.9-8.6)$ & $76(47-88)$ \\
\hline $\begin{array}{l}\text { Housekeeping and } \\
\text { cleaners }\end{array}$ & $9.0(4.0-20.1)$ & $89(75-95)$ & $143.4(42.3-485.3)$ & $99(98-100)$ \\
\hline $\begin{array}{l}\text { Data processing } \\
\text { operators } \\
\text { Material handlers }\end{array}$ & $\begin{array}{l}4.0(1.6-10.1) \\
7.5(3.2-17.8)\end{array}$ & $\begin{array}{l}75(38-90) \\
87(69-94)\end{array}$ & $\begin{array}{l}29.5(6.2-140.8) \\
12.3(3.7-41.1)\end{array}$ & $\begin{array}{l}97(84-100) \\
92(73-98)\end{array}$ \\
\hline Food and beverage: & & & & \\
\hline $\begin{array}{l}\text { Processing } \\
\text { Service } \\
\text { Child care }\end{array}$ & $\begin{array}{l}8.5(3.0-23.9) \\
4.6(2.1-10.3) \\
5.0(1.8-14.0)\end{array}$ & $\begin{array}{l}88(67-96) \\
78(52-90) \\
80(44-93)\end{array}$ & $\begin{array}{l}5.7(1.2-27.0) \\
7.9(1.0-63.9) \\
-\end{array}$ & $\begin{array}{l}82(17-96) \\
87(0-98)\end{array}$ \\
\hline Lorry and bus drivers & - & - & $6.4(2.2-18.6)$ & $84(55-95)$ \\
\hline
\end{tabular}

* Occupations: 3 and 4 digit categories from the Canadian standard occupational classification, 1980.

† Odds ratios obtained from multiple logistic regressions with surgery for carpal tunnel syndrome as the dependent variable and including age, sex, and occupation. The reference group included non-manual workers.

$\ddagger \mathrm{AFE}=$ attributable fraction in exposed people, represents the fraction of surgical CTS in each occupational group that is attributable to that occupation - that is, in excess compared with nonmanual workers.

$\$$ Manual workers include blue collar workers and white collar workers with manual work - such as nurses, waitresses, and bar staff, hairdressers, etc.

and beverage sector was the most highly represented with increased incidence both in the processing and in the service occupations. Child care occupations and transportation operators showed a risk of borderline significance. Child care included home based day care service providers. Transportation operators were restricted almost exclusively to lorry drivers.

Increased but not significant SIRs were found among hair dressers and specialised educators for exceptional or handicapped students (table 2). No excess risk was found among manufacturing occupations which include sewing machine operators (a large sector in Montreal), clerical workers (other than data processing operators), health care occupations, and construction workers. Because this study was done in an urban environment, occupa- tions in the primary industries (mining, fishing, forestry, and farming) were not represented.

Table 3 shows odds ratios (ORs) and their fractions attributable to occupations for all manual workers and each of the seven occupations with increased SIRs. Odds ratios were consistent with SIRs but slightly more increased because the comparison group consists of non-manual workers (OR) rather than the total population (SIR) which includes manual and non-manual workers as well as people not working. For all manual workers, the attributable fraction was $55 \%$ in women and $76 \%$ in men. In each specific occupational category, attributable fractions were all above $75 \%$ which indicates that $75 \%$ or more of surgical CTS in those occupations is attributable to work. The fractions attributable to occupation are slightly higher in men than in women except in the food and beverage processing occupations.

\section{Discussion}

Our annual surgical CTS incidence of 0.9/ 1000 and the sex distribution, were similar to those reported by Liss et $a l^{10}$ in Ontario, Canada and Vessey et $a l^{11}$ in the United Kingdom. The distribution of patients interviewed by age, sex, and geographical location where surgery was performed, was identical to that of all surgical cases of CTS on the island of Montreal. Only one patient refused to participate, so we are confident that the sample interviewed is representative of all surgical CTS. To our knowledge, no scientific data currently exist that find the proportion of surgical cases of CTS in the total cases of CTS. We suggest that it might be high because from the patient's point of view, surgery for CTS is an intervention that is readily available in Montreal, does not necessarily require a stay in hospital, and is completely covered by the provincial health insurance plan. From the medical point of view, there seems to be a consensus that CTS associated with severe symptoms and poor functional state is referred to a surgeon. In our population, $42 \%$ of the patients report having received no other form of treatment before surgery.

An important concern is potential referral bias. Rates of surgical CTS by occupation would be biased as estimators of underlying risk of CTS if physicians were more likely to refer patients in certain occupations for surgery or to refer them more quickly. We do not think that this played an important part in our study because the severity of symptoms and functional limitations in the week preceding surgery was comparable between workers and nonworkers, and between manual and non-manual workers. Also, we found no difference in the delay between the onset of symptoms and surgery between occupations, age, or sex. Thus, the indications for surgery seemed to be comparable. Moreover, as CTS is seldom recognised by the Quebec Workers' Compensation Board, there is little incentive for workers to file a claim. In fact, the total number of claims for CTS for the whole province was only 348 in 1995, for a rate of 0.13 cases $/ 1000$ 
workers, which is one 10th of that found in the province of British Columbia where CTS is recognised as an occupational disease.

Our analyses were controlled for age and sex but not for other potential confounders that are associated with employment and occupational or non-occupational risk factors. Also, absence from the workplace due to CTS, did not play a part in underestimating the number of cases in this study, because subjects were recruited from the surgeons' offices, irrespective of their work status. The available sample size provided a power of $90 \%$ to detect SIRs $\geqslant 2.0$ in occupational groups that constituted at least $5 \%$ of the workforce. ${ }^{12}$ Large SIRs were found in smaller groups of workers but their $95 \%$ CIs were wider.

The food and beverage processing occupations have been found to be at risk of a high incidence of CTS in previous studies with scientific evidence of a strong association between CTS and occupation. ${ }^{13-16}$ Other occupations identified at greater risk in our study that have been corroborated with less rigorous evidence include housekeeping, ${ }^{17-22}$ data processing, ${ }^{18}$ wrapping or packaging, ${ }^{17}$ food and beverage service occupations, ${ }^{23-18}$ and lorry driving. ${ }^{24}$ The results obtained for child care occupations are surprising. Perhaps the number of providers of home based day care services may have been underestimated in the denominator (number of people who declared to the Canadian census to be working as providers of child care) and thus, overestimating the SIR.

By estimating denominators we were able to compare rates of occurrence of disease, not just absolute numbers of cases. Studies that reported only numbers of cases by occupation cannot identify workers at greater risk. ${ }^{24}$ For example, in our study, clerical workers (except operators of data processing equipment), healthcare workers, and manufacturing occupations represented $32 \%$ of all cases of surgical CTS among those who had a job when symptoms first started. However, the incidences of surgical CTS found in those occupations were no greater than those for the total population.

Other studies have described the potential contribution of work related and personal medical factors to the development of CTS. The Centers for Disease Control ${ }^{26}$ and Miller et $a l^{27}$ reported respectively that $47 \%$ and $43 \%$ of workers diagnosed with CTS were exposed to at least one risk factor at work, findings similar to ours (53\%). Stevens et $a l^{28}$ reported that $57 \%$ of patients with CTS diagnosed at the Mayo Clinic, had one of the medical conditions known to be associated with the development of CTS, which is higher than in our study population $(40 \%)$, but the patients at the Mayo Clinic were probably a selected group. These proportions, however, are not mutually exclusive.

Hagberg et $a l^{29}$ calculated attributable fractions from relative risks published in 13 epidemiological studies that used a control group. The range of attributable fraction in those studies ranged between $50 \%$ and $90 \%$ of CTS that could be attributable to work. Those high numbers reflect the selection criteria used in the studies, which attempted to maximise the contrast between the exposed and non-exposed groups. Our calculation of attributable fraction in the seven occupations that showed an increased SIR, resulted in similarly increased values $(75 \%$ to $100 \%)$. These findings support the idea that occupational risk factors for CTS are concentrated in specific occupations. An important contribution of our study was the estimation of an attributable fraction for all occupations in which manual work is involved, in a population defined by a geographical territory without restriction on work or compensation.

\section{Conclusion}

Among manual workers on the island of Montreal, $55 \%$ of surgical CTS in women and $76 \%$ in men was attributable to work. Increased risk of surgical CTS was found in seven occupational groups.

We are indebted to the members of the research team Madeleine Bensoussan, Francine Bujold, Yvette Bonvalot, Suzette Clément, Francine Parent, and Linda Clermont for their dedication. The following investigators participated in the study: JL Beaudoin, G Beauregard, JP Bossé, J Bouchard, R Charbonneau, A Chollet, J Cohen, D Cunningham, JP Daigle, $R$ Delorme, A Desiardins, L Duranceau, G Frenette, $R$ Grossenbacher, C Kerrigan, L Duranceau, G Frenette, R Mouffarège, J Pelletier, and JY St-Laurent. This project was funded by the Quebec Institut de recherche en santé et sécurité du travail.

1 Hagberg $M$, Silverstein $B$, Wells $R$, Smith $M J$ Hendrick HW, Carayon P, Pérusse $M$. Evidence of work relatedness for selected nerve disorders: carpal tunnel syndrome, for selected nerve disorders: carpal tunnel syndrome, thoracic outlet syndrome, radiculopathy, vibration neu-
ropathy. In: Kuorinka I, Forcier L, ed. Work related musculoropathy. In: Kuorinka I, Forcier $\mathrm{L}$, ed. Work related musculo-
skeletal disorders (WMSDs): a reference book for prevention. skeletal disorders (WMSDs): a reference book

2 Katz JN, Stirrat CR, Larson MG, Fossel AH, Eaton HM, Liang MH. A self-administered hand symptom diagram for the diagnosis and epidemiologic study of carpal tunnel syndrome. F Rheumatol 1990;17:1495-8.

3 Katz JN, Punnett L, Simmons BP, Fossel AH, Mooney N, Deller RB. Workers' compensation recipients with carpal tunnel syndrome: the validity of self-reported health measures. Am $\mathcal{F}$ Public Health 1996;86:52-6.

4 Levine DW, Simmons BP, Koris MJ, Daltroy LH, Hohl GG, Fossel AH, Katz JN. A self-administered questionnaire for Fossel AH, Katz JN. A self-administered questionnaire for the assessment of severity of symptoms and functional status in carpal tun

5 Fleiss JL. Statistical methods for rates and proportions. New York, NY: John Wiley, 1981:237-55.

6 Bernard PM, LaPointe C. Statistical measures in epidemiology. Québec: Presses de l'Université Laval, 1987:287-8. (In French.)

7 Statistics Canada. Standard occupational classification 1980 Ottawa, Canada: Statistics Canada, 1981. (Cat 12-55E.)

8 Hébert F, Duguay P, Massicotte P, Levy M. Revised occupational categories for use in descriptive studies. Montreal Quebec: Quebec Research Institute in Occupational Health and Safety, 1995. (In French.)

9 Breslow NE, Day NE. Statistical methods in cancer research, vol 1: the analysis of case-control studies. Lyon: International vol 1: the analysis of case-control studies. Lyon

10 Liss GM, Armstrong C, Kusiak RA, Gailitis MM. Use of provincial health insurance plan billing data to estimate carpal tunnel syndrome morbidity and surgery rates. $A m \mathcal{F}$ Ind Med 1992;22:395-409.

11 Vessey MP, Villard-Mackintosh L, Yeates D. Epidemiology of carpal tunnel syndrome in women of childbearing age: findings in a large cohort study. Int $\mathcal{F}$ Epidemiol 1990;19: 655-9.

12 Breslow NE, Day NE. Statistical methods in cancer research, vol II: the design and analysis of cohort studies. Lyon: International Agency for Research on Cancer, 1987:273-9.

13 Chiang HC, Chen SS, Yu HS, Ko YC. The occurrence of carpal tunnel syndrome in frozen food factory employees. Kaohsiung fournal of Medical Science 1990;6:73-80.

14 Falck B, Aarnio P. Left-sided carpal tunnel syndrome in butchers. Scand $\mathcal{F}$ Work Environ Health 1983;9:291-7.

15 Schottland JR, Kirschberg GJ, Fillingin R, Davis VP, Hogg F. Median nerve latencies in poultry processing workers: an approach to resolving the role of industrial "cumulative trauma" in the development of carpal tunnel syndrome. $\mathcal{F}$ Occup Med 1991;33:627-31.

16 Franklin GM, Haug J, Heyer N, Checkoway H, Peck N. Occupational carpal tunnel syndrome in Washington state, 1984-8. Am f Public Health 1991;81:741-6. 
17 Lapidus PW, Fenton R. Stenosing tenovaginitis at the wrist and fingers. Report of 423 cases in 369 patients with 354 operations. American Medical Association Archives of Surgery 1952;64:475-87.

18 Phalen GS. The carpal tunnel syndrome: 17 years' experience in diagnosis and treatment of 654 hands. $\mathcal{f}$ Bone foint Surg 1966;48A:211-28.

19 Brooks DM. Nerve compression by simple ganglia. A review of 13 collected cases. F Bone foint Surg 1952;34B:391-400.

20 Grokoest AW, Demartinbi FE. Systemic disease and the carpal tunnel syndrome. $\mathcal{F} A M A$ 1954;155: 635-7.

21 Kendall $\mathrm{D}$. Aetiology, diagnosis, and treatment of paresthesia in the hands. $B M F$ 1960;2:1633-40.

22 Thompson AR, Plewes LW, Shaw EG. Peritendinitis crepitans and simple tenosynovitis: a clinical study of 544 cases in industry. $\mathrm{Br} \mathcal{F}$ Ind Med 1951;8:150-60.

23 Tanzer RC. The carpal tunnel syndrome: a clinical and anatomical study. F Bone foint Surg 1959;41A:626-34.
24 Tanaka S, Wild DK, Seligman J, Halperin WE, Behrens VJ, Putz-Anderson V. Prevalence and work-relatedness of selfreported carpal tunnel syndrome among US workers: analysis of the occupational health supplement data of 1988 national health interview survey. Am $₹$ Ind Med 1995 ; 27:451-70.

25 Shiller F, Kolb FO. Carpal tunnel syndrome in acromegaly. Neurology 1954;4:271-82.

26 Centers for Disease Control. Occupational disease surveillance: carpal tunnel syndrome. MMWR Morb Morta Wkly Rep 1989;38:485-9.

27 Miller RS, Iverson DC, Fried RA, Green LA, Nutting PA Carpal tunnel syndrome in primary care: a report from ASPN. $\mathcal{f}$ Fam Pract 1994;38:337-44.

28 Stevens JC, Beard CM, O'Fallon WM, Kurland LT. Conditions associated with carpal tunnel syndrome. Mayo Clin Proc 1992;67:541-8.

29 Hagberg M, Morgenstern H, Kelsh M. Impact of occupations and job tasks on the prevalence of carpal tunnel syndrome. Scand 7 Work Environ Health 1992;18:337-45.

\section{Correspondence and editorials}

Occupational and Environmental Medicine welcomes correspondence relating to any of the material appearing in the journal. Results from preliminary or small scale studies may also be published in the correspondence column if this seems appropriate. Letters should be not more than 500 words in length and contain a minimum of references. Tables and figures should be kept to an absolute minimum. Letters are accepted on the understanding that they be subject to editorial revision and shortening.

The journal also publishes editorials which are normally specially commissioned. The Editor welcomes suggestions regarding suitable topics; those wishing to submit an editorial, however, should do so only after discussion with the Editor. 